\title{
Vocal fold myxoma: a case report and review of current literature
}

\author{
Zuraini Mohammad Nasir ${ }^{1,2^{*}}$ (D), Mohd Hazmi Mohamed ${ }^{1,2}$, Ikmal Hisyam Bakrin³ and Loh Tze Liang²
}

\begin{abstract}
Background: Vocal fold myxoma is a rare mesenchymal tumor with unknown exact etiology. The aim of this report is to review current literature on demographic and clinical features of vocal fold myxomas in order to increase awareness among otorhinolaryngologists on management of this rare vocal fold pathology.

Case presentation: We report a case of a 46-year-old female teacher presented with 1 year history of progressive dysphonia with no airway obstructive or constitutional symptoms. Flexible laryngoscopy revealed a polypoid mass at the anterior two thirds of the left vocal fold. We proceeded with endolaryngeal microsurgery, where a left vocal fold mass with prominent overlying blood vessels was incompletely excised due to poor plane, in an attempt to prevent injury to vocal ligament. The histopathological findings were consistent with myxoma. No evidence of recurrence was noted at 2 months postoperatively.

Conclusions: Vocal fold myxoma should be considered as a differential diagnosis of vocal fold pathology clinically resembling vocal fold polyp, especially in older male adults. Complete excision with removal of a rim of surrounding tissue is the gold-standard treatment to prevent recurrence. If diagnosis is uncertain, intraoperative frozen section can be performed to ensure margins are free from tumor. Life-long follow-up is recommended in incomplete excision of tumor.
\end{abstract}

Keywords: Case report, Larynx, Laryngeal myxoma, Myxoma, Vocal fold

\section{Background}

Myxomas are rare benign neoplasms of uncertain mesenchymal cell origin that typically involve large muscles such as the heart [1]. In the head and neck region, they have been reported to occur as odontogenic tumors of maxilla and mandible [1, 2]. Myxomas originating from the larynx are rare and sites of involvement that have been reported include vocal fold, aryepiglottic fold, and epiglottis [3]. Myxomas rarely arise from vocal fold with only over twenty cases reported for the past 30 years through extensive literature search. The exact etiology of vocal fold myxoma remains unclear. It is believed that myxomas are likely to derive from primitive embryonic

\footnotetext{
*Correspondence: zuraininasir@upm.edu.my

${ }^{2}$ Otorhinolaryngology Department, Hospital Pengajar Universiti Putra

Malaysia, 43400 UPM, Serdang, Selangor, Malaysia

Full list of author information is available at the end of the article
}

mesenchyme or fibroblasts that are capable of elaborating abundant mucopolysaccharides [1]. Herein, we describe a case of vocal fold myxoma initially diagnosed as vocal fold polyp.

\section{Case presentation}

A 46-year-old female presented with 1 year history of progressive dysphonia. She worked as a teacher and had no significant medical and family history. There were no associated breathing or swallowing problems. Clinically, she appeared to be comfortable with no stridor or neck swellings. Maximum phonation time was normal (15 s), and she had overall dysphonia of grade 3 (roughness) on GRBAS scale [4]. Flexible laryngoscopy revealed an approximately $1.0 \times 1.0 \mathrm{~cm}$, round, pink, polypoid mass with smooth surface at the edge of anterior two thirds of the left membranous vocal fold (Fig. 1). Vocal fold mobility was normal, and there were no other abnormal 


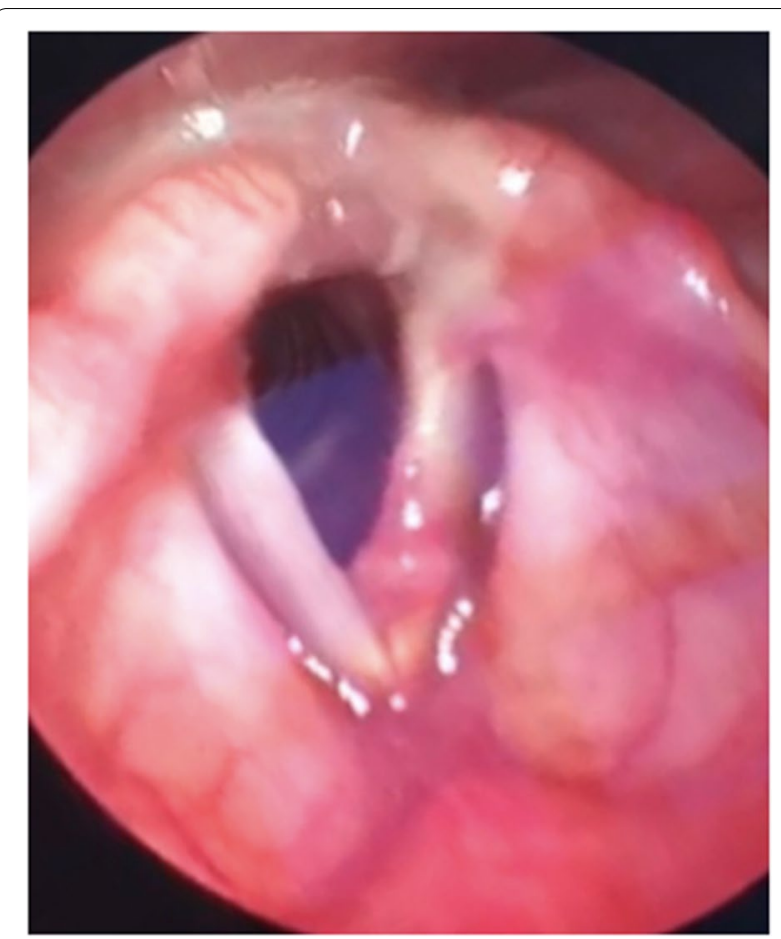

Fig. 1 Indirect laryngoscopy view showing polypoid mass at anterior two thirds of the left membranous vocal fold

laryngeal findings. Provisional diagnosis given was left vocal fold polyp in view of her profession and laryngoscopy findings. We proceeded with endolaryngeal microsurgery using precision technique, where intraoperatively there was a $1.0 \times 1.0 \mathrm{~cm}$ mass at left vocal fold with prominent overlying blood vessels (Fig. 2). After raising medial microflap, difficulty was encountered in removing the entire mass as it extended towards vocal ligament with no clear plane, appearing as edematous tissue within superficial lamina propria. Small fragments of tissue close to vocal ligament were not removed in an attempt to preserve vocal function.

Microscopically, the lesion showed hypocellular myxoid-rich area alternating with more cellular area (Fig. 3). The myxoid-rich area showed presence of scattered bland spindle cells accompanied with presence of thin walled linear or curvilinear-like blood vessel. The cellular areas were composed of moderately cellular bland ovoid to spindle cells with eosinophilic cytoplasm and indistinct cell boundary embedded within a variably collagenized stroma. No nuclear pleomorphism, necrosis, or mitosis was detected (Fig. 4). The histopathological findings of the lesion were consistent with myxoma. Further immunohistochemical study showed the spindle cells are negative for cytokeratin AE1/AE3, epithelial membrane antigen

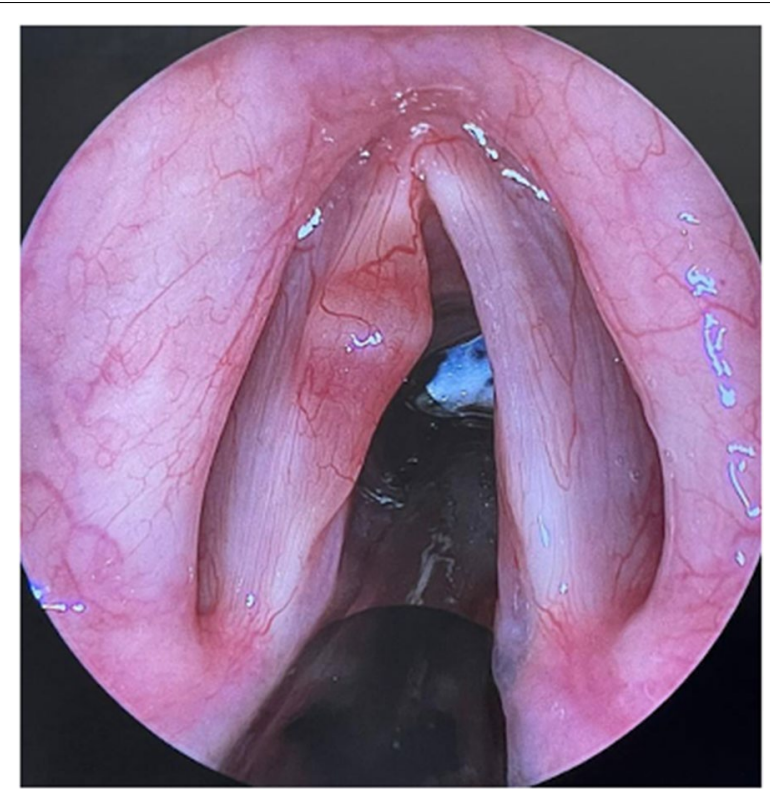

Fig. 2 Direct laryngoscopy view showing fusiform polypoid mass at left vocal fold with prominent overlying blood vessels. Note the fullness surrounding the mass within the superficial lamina propria

(EMA), desmin, actin, CD34, and S100. Full physical examination was performed to rule out heritable diseases that are associated with vocal fold myxoma such as Carney complex, Mazabraud syndrome, and Hunter's syndrome. Two months postoperatively, patient's hoarseness has improved with overall dysphonia of grade one (roughness) on GRBAS scale [4]. Laryngoscopic examination showed mild edema over the left membranous vocal fold at the operated site, and there was no residual mass visualized. The patient was

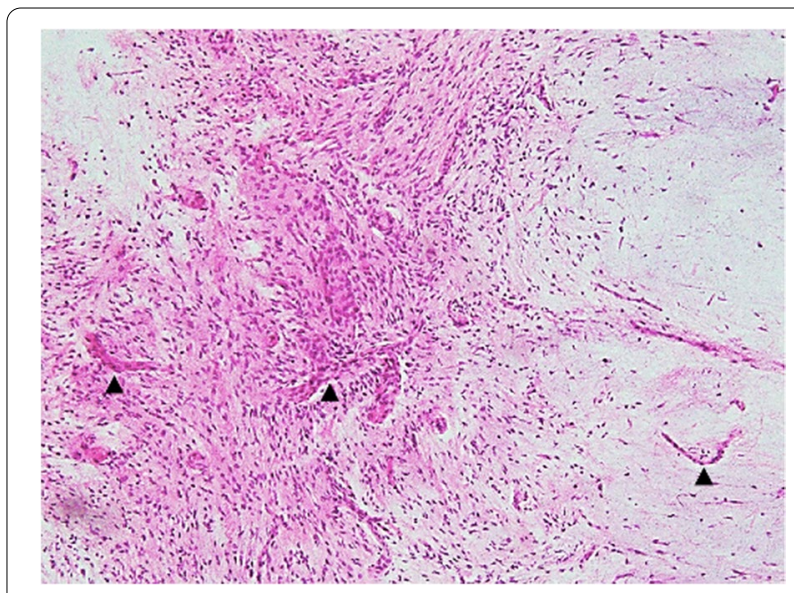

Fig. 3 Alternating myxoid and cellular spindle shaped cells with occasional curvilinear-like blood vessels (arrow head) (hematoxylin and eosin stain, original magnification $\times 100$ ) 


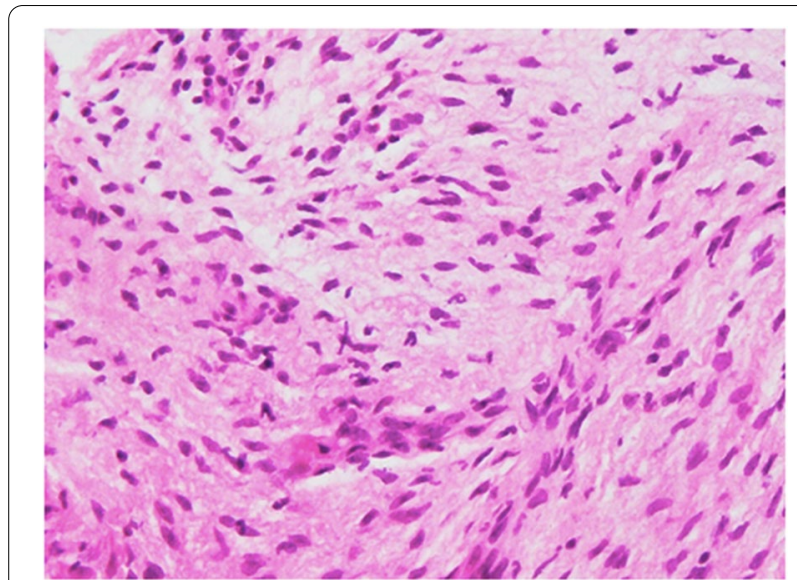

Fig. 4 The spindle shaped cells showed normochromic nuclei with inconspicuous nucleoli and indistinct eosinophilic cytoplasm. No nuclear pleomorphism, mitosis, or tumor necrosis were observed (hematoxylin and eosin stain, original magnification $\times 400$ )

informed of the difficulty encountered intraoperatively and advised for life-long follow-up. She was satisfied with the treatment given.

\section{Discussion}

Historically, myxoma was first described by Virchow in 1871 as a group of tumors that resemble mucinous substance of umbilical cord [5]. In 1948, Stout further elucidated myxoma as non-metastasizing true mesenchymal neoplasm consisting of undifferentiated stellate cells in a loose myxoid stroma [5]. This forms the basis of current histological description, and a diagnostic criterion was also outlined.

Based on our review, vocal fold myxomas show strong male preponderance, with 20 out of 23 cases reported occurred in males (Table 1) [1-3, 6-12, 1521]. Patients' ages ranged from 25 to 77 years old and tend to occur in older adults between 5 th to 7 th decades. Mode of presentation generally depends on size of tumor. Lesions measuring less than $1.5 \mathrm{~cm}$ commonly present with progressive dysphonia. Larger lesions measuring more than $1.5 \mathrm{~cm}$ are more likely to present with upper airway obstruction such as dyspnea and stridor. Two of the reported cases required emergency tracheostomy to secure airway $[9,17]$. On laryngoscopic examination, vocal fold myxoma usually appears as broad-based, hypervascular, and polypoid

Table 1 Summary of reported cases of vocal fold myxoma

\begin{tabular}{|c|c|c|c|c|c|c|c|c|}
\hline Case [ref] & Year & Age & Gender & Site & Size $(\mathrm{cm})$ & Main symptom & Removal & Recurrence \\
\hline $1[6]$ & 1982 & 30 & M & Left & 0.75 & Dysphonia & Complete & None (12 months) \\
\hline $2[6]$ & 1982 & 25 & $\mathrm{~F}$ & Right & 1.5 & Dysphonia & Complete & None (12 months) \\
\hline $3[7]$ & 1994 & 64 & M & Left & 1.0 & Dysphonia & Incomplete & None (18 months) \\
\hline $4[8]$ & 1997 & 57 & M & Right & 0.7 & Dysphonia & Complete & None (6 months) \\
\hline $5[9]$ & 1997 & 62 & M & Right & 2.5 & Dyspnea, stridor (requiring tracheostomy) & Complete & - \\
\hline $6[10]$ & 1999 & 42 & M & - & - & Dyspnea, OSA & - & None (12 months) \\
\hline $7[11]$ & 2005 & 46 & M & Right & 0.8 & Dysphonia & Complete & - \\
\hline $8[12]$ & 2007 & 53 & M & Right & 0.5 & Dysphonia & Complete & - \\
\hline $9[13]$ & 2008 & 48 & $\mathrm{~F}$ & Left & - & Dysphonia & - & None (3 months) \\
\hline $10[14]$ & 2008 & 74 & $\mathrm{~F}$ & Right & 0.4 & Dysphonia, dyspnea & Complete & None (24 months) \\
\hline $11[15]$ & 2008 & 36 & M & Right & 0.7 & Dysphonia & - & - \\
\hline $12[16]$ & 2013 & 61 & M & Right & 0.5 & Dysphonia & Complete & None (3 monthly) \\
\hline $13[1]$ & 2014 & 77 & M & Left & 0.8 & Dysphonia & - & None (3 months) \\
\hline $14[17]$ & 2014 & 64 & M & Right & 1.5 & Dyspnea, stridor (requiring tracheostomy) & - & None (8 months) \\
\hline $15[18]$ & 2015 & 60 & M & Right & 1.0 & Dysphonia & Incomplete & Recurrence at 27 months \\
\hline 16 [19] & 2018 & 44 & M & Right & - & Dysphonia & Complete & None (18months) \\
\hline $17[19]$ & 2018 & 77 & M & Left & - & Dysphonia & Complete & None at 3 months \\
\hline $18[20]$ & 2018 & 53 & M & Right & 0.5 & Dysphonia & - & - \\
\hline 19 [3] & 2020 & 69 & M & Right & 0.9 & Dysphonia & Complete & None (1 month) \\
\hline $20[2]$ & 2020 & 36 & M & - & - & Dysphonia & - & None (6 months) \\
\hline $21[2]$ & 2020 & 45 & M & - & - & Dysphonia & - & None (6 months) \\
\hline $22[2]$ & 2020 & 72 & M & - & - & Dysphonia & - & None (6 months) \\
\hline $23[21]$ & 2021 & 54 & M & Right & 1.5 & Dysphonia, dyspnea, stridor & Complete & - \\
\hline $24[-]$ & Present case & 46 & $\mathrm{~F}$ & Left & 1.0 & Dysphonia & Incomplete & None (2 months) \\
\hline
\end{tabular}


mass $[1,2]$. It usually arises superficial to vocal ligament at variable sites of vocal fold including anterior commissure $[1,2]$. Stroboscopic examination may display loss of mucosal wave $[7,8]$. It is important to perform complete physical examination as myxomas can be associated with heritable disease such as Carney complex, Mazabraud syndrome, and mucopolysaccharidosis II (MPS II) or Hunter's syndrome [1]. Recurrence of tumor has only been reported once in this review.

Diagnosis of myxoma is made through histopathological examination. Histologically, laryngeal myxomas can be described as pure myxoma and myxoma of cellular variant [21]. Classic myxoma is characterized by bland spindle and stellate shaped cells embedded in hypovascular, abundant loose myxoid stroma, whereas myxoma of cellular variant is characterized by hypercellularity, more numerous collagen fibers, and increased vascularity [21]. Important histological differential diagnoses to consider are other soft tissue tumors with myxoid degeneration such as myxoid liposarcoma, myxoid leiomyosarcoma, ganglions, and rhabdomyosarcoma [22]. The absence of stromal vasculature, hemorrhage, hemosiderin-laden macrophages, and hyalinization of basement membrane can help to distinguish myxomas from vocal fold polyps [1].

The treatment of laryngeal myxoma is complete excision of the tumor with removal of a rim of surrounding normal tissue [2]. This is due to infiltrative growth pattern and presence of pseudocapsule in myxomas where incomplete excision will inevitably lead to local recurrence [2]. In doing so, intra-operative frozen section has been found to be beneficial for immediate assessment of margin status to ensure complete excision [9]. Endoscopic laryngeal microsurgery with careful excision of tumor is pertinent to preserve the integrity of vocal ligament and vocal function. An external thyrotomy approach has been described where the vocal fold myxoma was adherent to the undersurface of vocal ligament [18]. The tumor was not completely excised to prevent injury to the vocal ligament and recurrence was noted after 27 months [18]. Long-term follow-up is recommended due to its infiltrative nature, slow growth rate, and high incidence of local recurrence [13].

This case report describes a rare occurrence of myxoma arising from vocal fold with largest compilation of cases to date of over twenty cases for the past 30 years. Previous demographic findings and intraoperative techniques employed were also analyzed. The limitation of this report is that long term follow-up is not available to observe for recurrence.

\section{Conclusions}

Vocal fold myxoma should be considered as a differential diagnosis of vocal fold pathology clinically resembling vocal fold polyp, especially in older male adults. Complete excision with removal of a rim of surrounding tissue is the gold-standard treatment to prevent recurrence. If diagnosis is uncertain, intraoperative frozen section may play a role in employing appropriate surgical technique and to ensure margins are free from tumor. Life-long follow-up is recommended in incomplete excision of tumor.

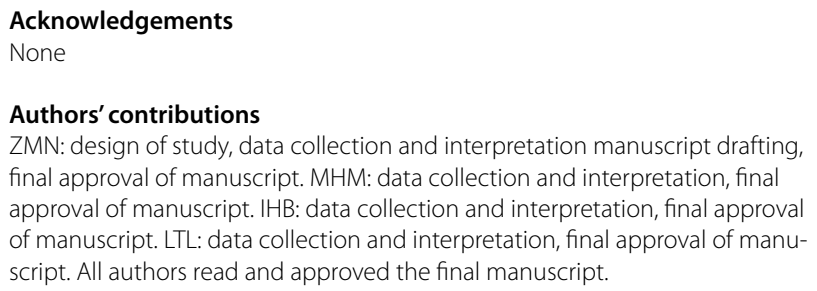

Availability of data and materials

Not applicable

\section{Declarations}

Ethics approval and consent to participate Not applicable

\section{Consent for publication}

Written informed consent was obtained from the patient for publication of this case report and accompanying images.

\section{Competing interests}

The authors declare that they have no competing interests.

\section{Author details}

${ }^{1}$ Otorhinolaryngology Department, Faculty of Medicine \& Health Sciences, University Putra Malaysia, 43400 UPM, Serdang, Selangor, Malaysia. ${ }^{2}$ Otorhinolaryngology Department, Hospital Pengajar Universiti Putra Malaysia, 43400 UPM, Serdang, Selangor, Malaysia. ${ }^{3}$ Pathology Department, Faculty of Medicine \& Health Sciences, University Putra Malaysia, 43400 UPM, Serdang, Selangor, Malaysia.

Received: 22 September 2021 Accepted: 28 January 2022 Published online: 19 February 2022

\section{References}

1. Ritchie A, Youngerman J, Fantasia JE, Kahn L, Cocker RS (2014) Laryngeal myxoma: a case report and review of the literature. Head Neck Pathol 8:204-208. https://doi.org/10.1007/s12105-013-0485-5

2. Hong YT, Hong KH (2020) Localized laryngeal myxoma: laryngoscopic features. Ear Nose Throat J 99(5):NP56-NP57. https://doi.org/10.1177/ 0145561319840234

3. Val-Bernal JF, Martino M, Longarela MY (2020) Cellular myxoma of the vocal cord: a case report and review of the literature. Turk Patoloji Derg 36(1):77-81. https://doi.org/10.5146/tjpath.2017.01417

4. Hirano M (1981) "GRBAS" scale for evaluating the hoarse voice \& frequency range of phonation. Clin Exam Voice 5:83-84

5. Stout AP (1948) Myxoma, the tumor of primitive mesenchyme. Ann Surg 127(4):706-719 
6. Malik MK, Kumar A, Bhatia BPR (1982) Myxoma of the larynx. Ind J Otol 34:15-16. https://doi.org/10.1007/BF02994378

7. Hadley J, Gardiner Q, Dilkes M, Boyle M (1994) Myxoma of the larynx: a case report and review of the literature. J Laryngol Otol 108:811-812. https://doi.org/10.1017/s002221510012821x

8. Tsunoda K, Nosaka K, Housui M, Murano E, Ishikawa M, Imamura Y (1997) A rare case of laryngeal myxoma. J Laryngol Otol 111:271-273. https:// doi.org/10.1017/s0022215100137053

9. Kim KM, Kim SC, Jeong HJ, Kie JH (1997) Myxoma: life-threatening benign nonepithelial tumor of the larynx. Yonsey Med J 38:187-189. https://doi. org/10.3349/ymj.1997.38.3.187

10. Orliaguet O, Pépin JL, Veale D, Kelkel E, Pinel L, Lévy P (1999) Hunter's syndrome and associated sleep apnea cured by CPAP and surgery. Eur Respir J 13:1 195-1197. https://doi.org/10.1034/j.1399-3003.1999.13e42.x

11. Idrees MT, Hessler R, Terris D, Mixson C, Wang BY (2005) Unusual polypoid laryngeal myxoma. Mt Sinai J Med 72(4):282-284

12. Leu G, Klein AM, Deyrup AT, Johns MM 3rd (2007) Pathology quiz case 1. Laryngeal myxoma. Arch Otolaryngol Head Neck Surg 133(1):94-96. https://doi.org/10.1001/archotol.133.1.94

13. Ali S, MacDougall G, Wallace W (2008) Myxoma-rare laryngeal presentation. Internet J Otorhinolaryngol 11:1-4

14. Nakamura A, Iguchi $H$, Kusuki M, Yamane H, Matsuda M, Osako S (2008) Laryngeal myxoma. Acta Otolaryngol 128:110-112. https://doi.org/10. 1080/00016480701361970

15. Song YS, Jang S-H, Min KW, Na W, Jang SM et al (2008) Myxoma of the larynx presenting as a nodule. Korean J Pathol 42:306-307

16. Garca MF, Cankaya H, Turan M, Kosem M (2013) Laryngeal myxoma resembling a laryngeal polyp: case report. Van Tip Dergisi 20(2):100-102

17. Singh B, Uddesh SK (2014) Laryngeal myxoma: emergency management. Natl J Med Res 4:175-177

18. Tang CG, Monin DL, Puligandla B, Cruz RM (2015) Glottic myxoma presenting as chronic dysphonia: a case report and review of the literature. Ear Nose Throat J 94(1):E30-E33. https://doi.org/10.1177/0145561315 09400103

19. Imaizumi M, Tada Y, Tani A, Ikeda M, Nakaegawa Y et al (2018) Two cases of laryngeal myxoma misdiagnosed as a vocal fold polyp. J Otol Rhinol 7:1. https://doi.org/10.4172/2324-8785.1000332

20. Panda S, Kumar R, Gopinath VR (2018) Sagar P (2018) Head and neck myxoma presenting as isolated laryngeal polyp. Case Rep Otolaryngol. https://doi.org/10.1155/2018/6868737

21. Yu TT, Yu H, Cui Y, Liu W, Cui XY, Wang X (2021) Laryngeal myxoma: a case report. World J Clin Cases 9(12):2823-2829. https://doi.org/10.12998/ wjcc.v9.112.2823

22. Chen KTK, Ballecer RA (1986) Laryngeal myxoma. Am J Otolaryngol 7(1):58-59

\section{Publisher's Note}

Springer Nature remains neutral with regard to jurisdictional claims in published maps and institutional affiliations.

\section{Submit your manuscript to a SpringerOpen ${ }^{\circ}$ journal and benefit from:}

- Convenient online submission

- Rigorous peer review

- Open access: articles freely available online

- High visibility within the field

- Retaining the copyright to your article

Submit your next manuscript at $\boldsymbol{\text { springeropen.com }}$ 